УДК 621

ВАК 05.02.08
Ключевые слова: сборка, эффективность производства, сборочное производство, оборудование на агрегатно-модульной основе, технологичность, системы CAD/ САM/САРР, САПР, точность сборки

\title{
СБОРОЧНОЕ ПРОИЗВОДСТВО: ПРОБЛЕМЫ И РЕШЕНИЯ
}

\section{Статья посвящена 155-летнему юбилею Московского Политеха}

Михаил ВАРТАНОВ, Чан ЧУНГ ТА

Приведен анализ существующих проблем сборочного производства в машиностроении. Выявлены вопросы, требующие решения на отраслевом и государственном уровнях.

Сборка является заключительным этапом производства и, следовательно, определяет качество изделий. Проблема качества сборки в настоящее время является критически важной для машиностроения.

Сборка имеет значительные резервы в повышении эффективности производства. Уровень автоматизации сборки в России в настоящее время составляет 7-8\%, в Западной Европе и США - около $12 \%$, в Японии - 15-18\%. Сборочные работы остаются малопроизводительными, трудоемкими и дорогостоящими, поэтому повышается стоимость выпускаемых изделий и снижается качество.

Сборка взаимосвязана со всеми предшествующими этапами производства. Например, нарушение точности изготовления ведет к отказам, заклиниванию деталей при автоматической сборке. Проблемы с качеством определяются и тем, что на сборке часто трудятся рабочие невысокой квалификации, не имеющие необходимых контрольно-измерительных средств. Низкая надежность и большой процент отказов машин и приборов вызваны дефектами некачественной сборки.

Основными проблемами сборочного производства традиционно считаются [1]: $\rightarrow$ недостаточный уровень развития теории и технологии автоматизации сборки;

$\rightarrow$ нетехнологичность конструкций машин; $\rightarrow$ многообразие видов соединений и условий сборки, значительно затрудняюее создание универсального сборочного оборудования;

$\rightarrow$ необходимость высокоточного относительного взаимного ориентирования деталей перед сопряжением;

$\rightarrow$ большое разнообразие размерных, кинематических и динамических связей в машинах;

$\rightarrow$ сложности создания сборочного оборудования для современного многономенклатурного производства;

$\rightarrow$ традиции создания автоматического оборудования под действующее неавтоматизированное производство;

$\rightarrow$ отсутствие в России централизованного производителя модульного сборочного оборудования;

$\rightarrow$ сохраняющийся разрыв между конструкторской и технологической подготовкой производства, приводящий к потере информации;

$\rightarrow$ несовершенство нормативных документов, регламентирующих вопросы обеспечения качества сборки.

Совершенствование сборки ведется по следующим направлениям [2]:

$\rightarrow$ повышение технологичности конструкций собираемых изделий при сборке;

$\rightarrow$ сближение областей конструирования, изготовления деталей, сборки и управления на основе идеологии $\mathrm{CAD} / \mathrm{CAM} / \mathrm{CAE}$; 
$\rightarrow$ модульный принцип построения изделий;

$\rightarrow$ создание и внедрение новых способов сборки;

$\rightarrow$ автоматизация и роботизация сборочных процессов;

$\rightarrow$ разработка и внедрение адаптивного сборочного оборудования;

$\rightarrow$ проектирование технологии сборки с учетом технологической наследственности.

Основным направлением создания технологического оборудования является построение оборудования на агрегатно-модульной основе на базе ограниченной группы нормализованных узлов (технологических модулей), из которых можно компоновать технологическое оборудование различного целевого назначения. Наиболее известными производителями сборочного оборудования в мире являются следующие компании: Bosch (Германия), Renault (Франция), Sormel (Франция), Hitachi (Япония), Citizen Watch (Япония), Sortimat (Германия), НПО «Автопромсборка» (Беларусь). В Германии ежегодно проходит выставка сборочного оборудования.

В четырех странах мира издаются специализированные научно-технические журналы в области сборки машин и приборов (Россия, Польша, Великобритания и США). В России и за рубежом регулярно проводятся научно-технические конференции и семинары в области технологии сборки.

В условиях мелко- и среднесерийного производства высокий уровень эффективности сборочных операций может быть достигнут в условиях применения гибких сборочных систем, которые создаются на базе переналаживаемого технологического оборудования. Гибкость оборудования важна и в условиях массового производства. Особо сложной задачей является автоматизация и роботизация сборочного производства.

\section{АНАЛИЗ ТЕХНОЛОГИЧЕСКИХ ТРЕБОВАНИЙ К ИЗДЕЛИЮ И ВЫЯВЛЕНИЕ СБОРОЧНЫХ ЗАДАЧ}

Проектирование технологии сборки начинают с анализа исходных данных. К исходным данным относят рабочую конструкторскую документацию, программу выпуска, предполагаемую продолжительность выпуска изделия, имеющиеся производственные ресурсы, каталоги на сборочное оборудование и оснастку, имеющиеся процессы-аналоги, рекомендации по технологическим режимам сборки и технологические инструкции.

Основными технологическими задачами, которые должны учитываться и обеспечиваться технологическим процессом, являются [3]:

$\rightarrow$ точность взаимного расположения узлов и деталей;

$\rightarrow$ точность их линейных и угловых перемещений; $\rightarrow$ плотность и герметичность стыков;

$\rightarrow$ температурный режим работы;

$\rightarrow$ точность закрепления (силового замыкания);

$\rightarrow$ уравновешенность узлов и механизмов (точность балансировки);

$\rightarrow$ точность момента затяжки резьбовых соединений (в том числе групповых).

В отдельных случаях к изделиям могут предъявляться специфические функциональные требования (виброакустические, ресурсные, расход топлива и др.).

В настоящее время имеется ряд методологических проблем, связанных с нарушением принципов передачи достоверной информации при конструкторско-технологической подготовке производства. Основной проблемой, по мнению компании ADEM [4], является отсутствие ГОСТа на формат 3D-модели, содержащей конструкторские данные (фактическая геометрия детали, пространственные отклонения, шероховатость и т.д.). Необходим также ГОСТ на формат цифровых баз, содержащих технологические данные. Во внутренней архитектуре новой версии ADEM 10x заложен потенциал развития системы, более полно отвечающий требованиям концепции «Индустрия 4.0». Однако данная методология охватывает только механическую обработку.

\section{ТЕХНОЛОГИЧНОСТЬ КОНСТРУКЦИЙ ИЗДЕЛИЙ ПРИ СБОРКЕ}

Обеспечение технологичности изделий возможно при установлении взаимосвязей между конструкцией и технологией. Однако до настоящего времени обеспечение технологичности остается наименее формализованной задачей технологической подготовки производства, решение которой реализуется эвристическими методами и зависит от квалификации специалистов. Такая ситуация не соответствует потребностям производства, так как обуславливает возникновение дополнительных затрат, сдерживает возможности автоматизации сборки. После подготовки конструкторской документации эффективность отработки конструкции на технологичность резко падает, так как в этом случае принципиальные изменения невозможны и максимальный эффект не достигается.

К сожалению, не решают эту проблему и современные системы САПР. Вместе с тем ясно, что решение может быть найдено на основе интеграции CAD/ CAM/CAPP-систем. Примером такой системы может быть подход, изложенный в [5]. В модуле CAD использовано программное обеспечение SolidWorks, а в остальных модулях пакет программного обеспечения DFMA (Design for Manufacturing and Assembly) фирмы Boothroyd and Dewhurst Inc. (США). 


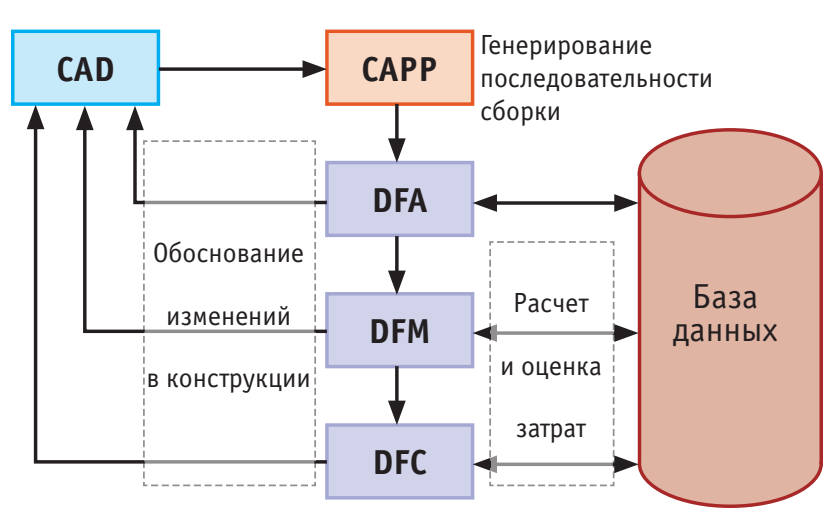

Puc. 1. Концепция САПР на основе методологии DFMA

Концепция данной САПР приведена на рис. 1. Однако методология DFMA позволяет лишь сравнивать два и более технических решения по изделию с позиции затрат в механообработке и сборке (в том числе и автоматической). При этом за рамками методологии остается выявление технологических недостатков в конструкции машины.

Наш подход к подготовке сборочного производства основан на параллельном конструкторско-технологическом проектировании [6]. Цель такого подхода - исключить необходимость перепроектирования изделия, сократить сроки подготовки производства и затраты самого производства. Однако это требует наличия соответствующих методик и процедур. Нами предложены две методики к решению проблемы: на основе технологического совершенствования прототипа и на основе формирования множества технических решений и их последующей оптимизации (рис. 2).

\section{ТЕХНОЛОГИЧЕСКОЕ ОБЕСПЕЧЕНИЕ КАЧЕСТВА СБОРКИ}

В настоящее время принято делить методы обеспечения качества сборки на две группы: пассивные и активные (рис. 3). С позиции автоматической сборки они далеко не равноценны. Общепринято, что наиболее отвечающим требованиям автоматической и роботизированной сборки является метод полной взаимозаменяемости. Это обусловило его широкое применение в автостроении. В станкостроении широкое применение получил метод неполной взаимозаменяемости.

Обусловлено это, в большинстве случаев, как точностью сборки, так и экономическими причинами. В подшипниковой промышленности получил применение метод селективной сборки. Выбор метода достижения точности сборки определяется соотношением между конструкторским и технологическим допусками. Например, групповую взаимозаменяемость применяют при сборке шатунно-поршневой группы автомобильных двигателей. Современное развитие этот метод получил при асимметричном распределении размеров сопрягаемых деталей (рис. 4).

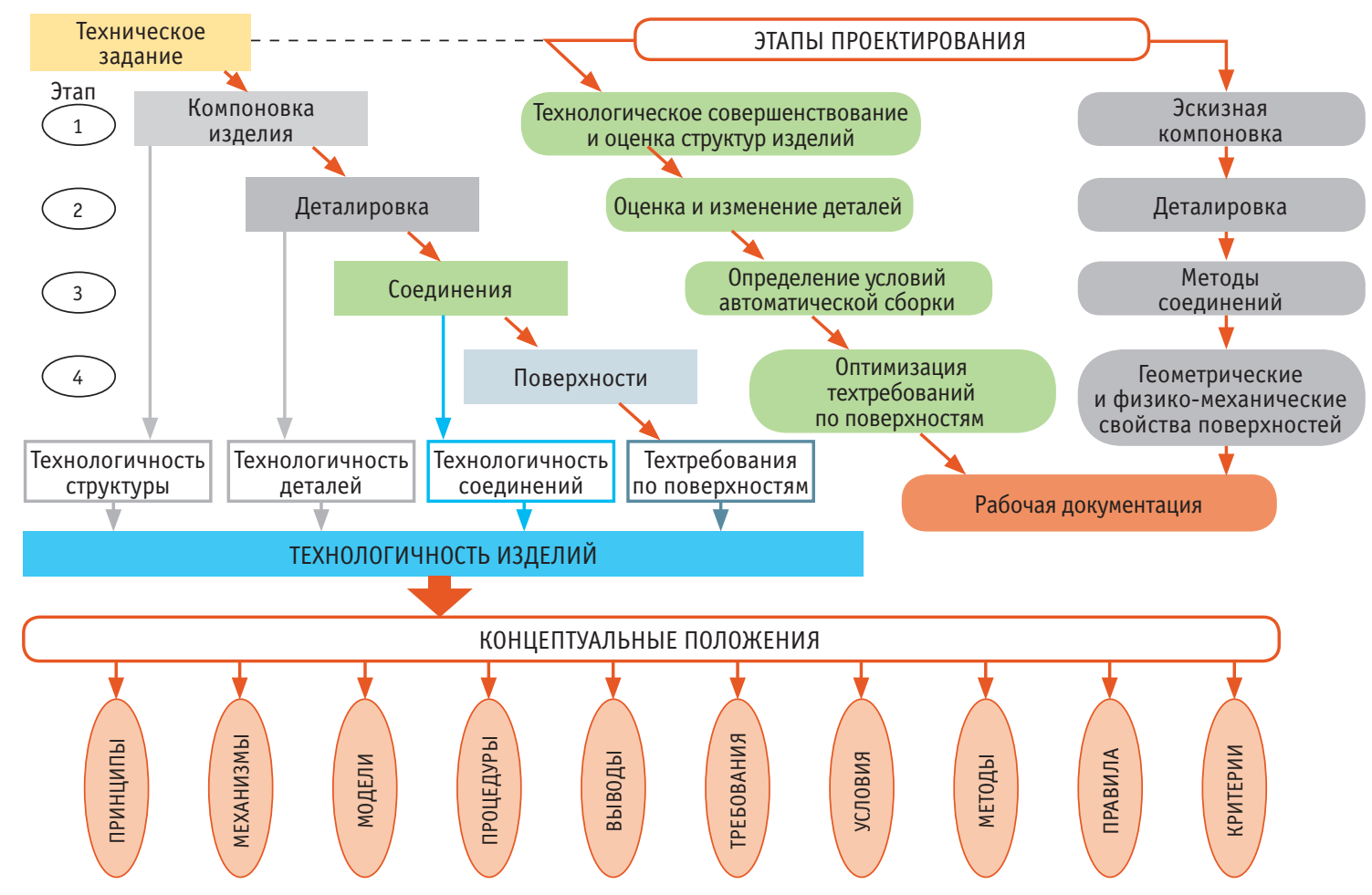

Puc. 2. Методология параллельного конструкторско-технологического проектирования 


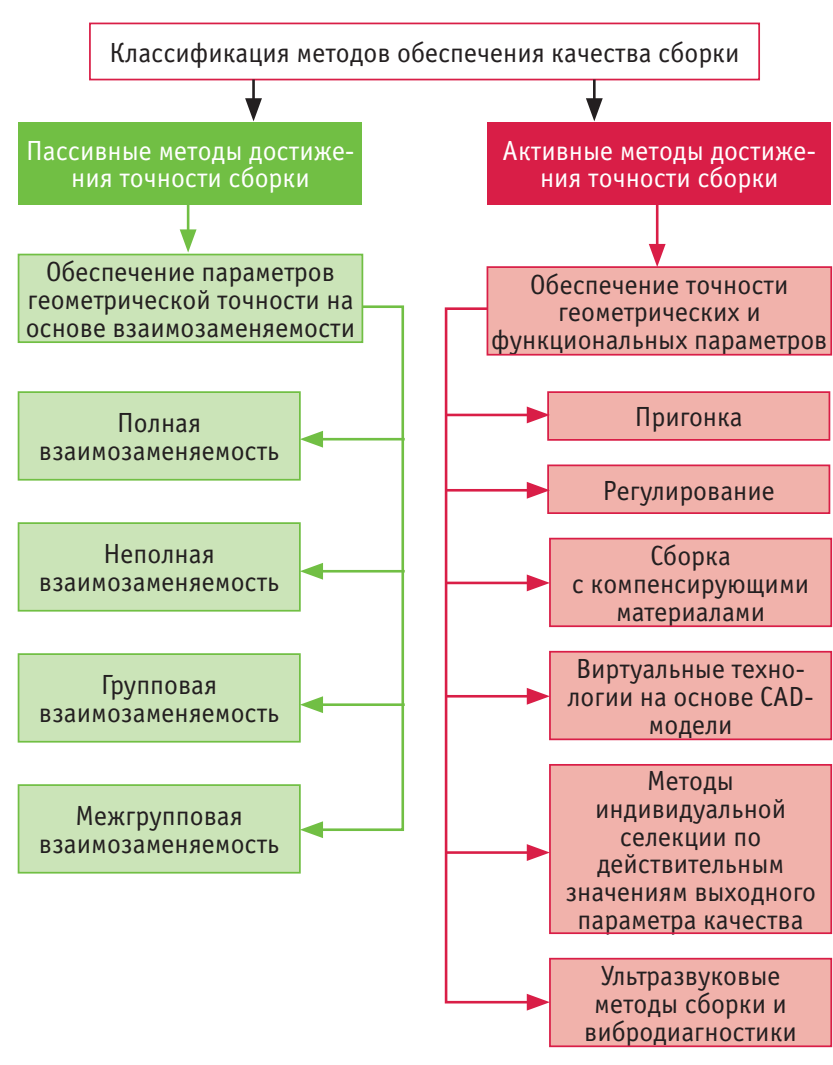

Puc. 3. Классификация методов обеспечения точности

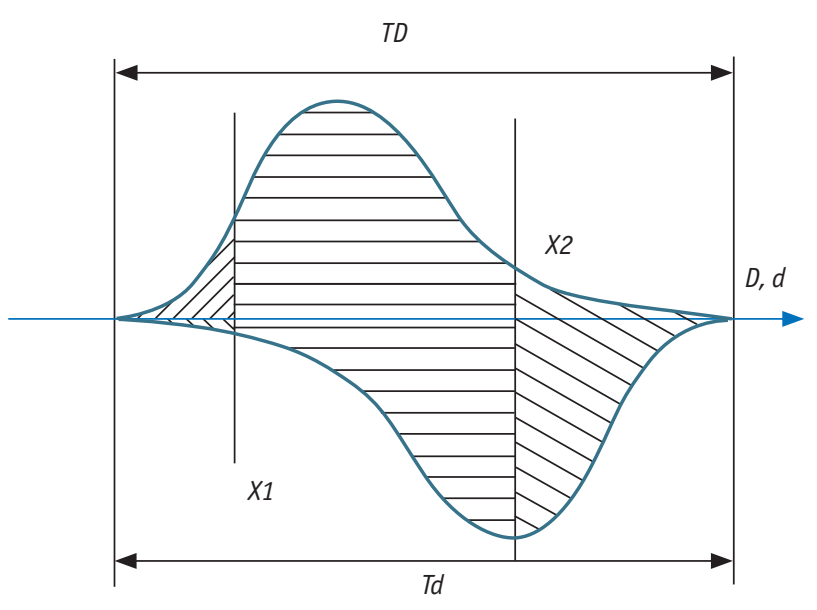

Puc. 4. Асимметричный характер законов распределения точности звеньев

Применение классической селективной сборки при асимметричном распределении приводит к большому объему незавершенного производства, что является проблемой (рис. 5). Существенно уменьшить объем незавершенного производства помогает применение метода межгрупповой взаимозаменяемости (рис. 6) [7, 8]. В настоящее время метод нашел свое применение при производстве

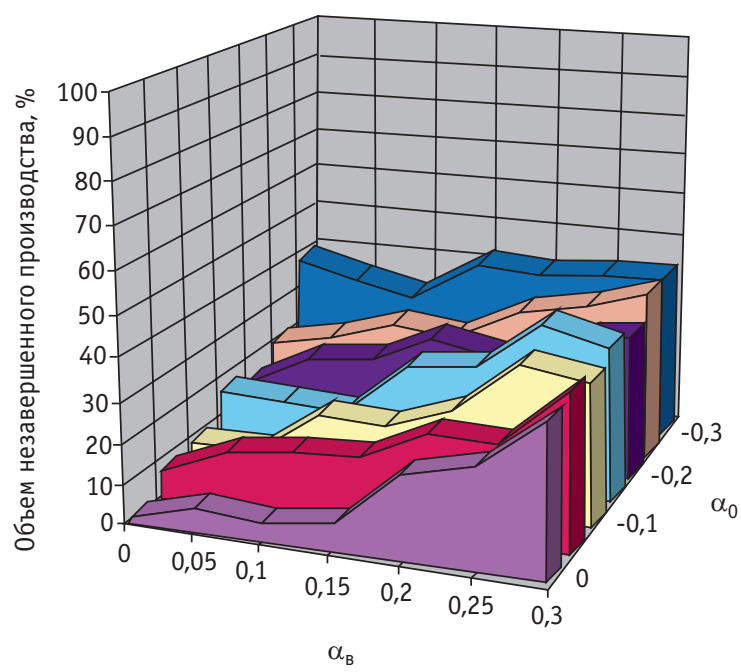

\begin{tabular}{|l|l|}
\hline Параметр & 3начение \\
\hline Допуск, ITA=ITB, мкм & 150 \\
\hline Максимальный зазор, $S_{\text {max }}$ мкм & 150 \\
\hline Минимальный зазор, $S_{\text {min' }}$ мкм & 50 \\
\hline Групповые допуски, $a=b=$ ITB/2, мкм & 50 \\
\hline Количество групп, $n_{1}=n_{2}$ & 3 \\
\hline $\begin{array}{l}\text { Нижнее предельное отклонение разме- } \\
\text { ра вала (поршня), мкм }\end{array}$ & -75 \\
\hline $\begin{array}{l}\text { Закон распределения размеров вала } \\
\text { (поршня) }\end{array}$ & Нормальный \\
\hline $\begin{array}{l}\text { Закон распределения размеров отвер- } \\
\text { стия (цилиндра) }\end{array}$ & Нормальный \\
\hline Объем производства, шт. & 200 \\
\hline
\end{tabular}

Puc. 5. Определение некомплектных деталей при достижении точности методом групповой взаимозаменяемости

горного оборудования. Однако, он может быть эффективен и в станкостроении.

Вторую группу методов принято называть «активными». Название связано с тем, что мы активно влияем на формирование точности изделия. К данным методам относят пригонку, регулирование, сборку с компенсирующими материалами, применение виртуальных моделей, метод индивидуальной селекции и ультразвуковые методы достижения качества. В ряде случаев в промышленности приходится применять методы пригонки деталей. Как правило, необходимость применения данного метода связана с очень высокой точностью деталей. Такая ситуация имеет место при производстве авиационных двигателей, автомобилей представительского класса. Это приводит к возрастанию трудоемкости сборки, а в ряде случаев неоднократным переборкам изделий. Выходом из этой ситуации 


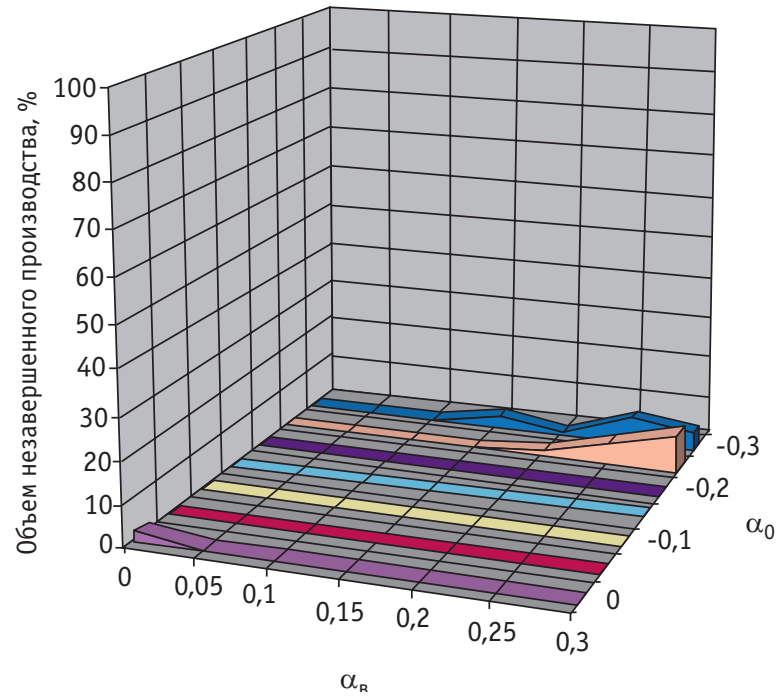

Puc. 6. Определение некомплектных деталей при достижении точности методом межгрупповой взаимозаменяемости

может быть применение метода функциональной взаимозаменяемости, разработанного в Рыбинском авиационном техническом университете [9]. Физическая сущность метода определяется не размерной точностью изделия, а его выходными параметрами. Метод позволяет существенно повысить точность сборки изделий. В последнее время получает развитие виртуальная сборка на основе CAD моделей деталей. Особенно эффективны такие решения при сборке сложнопрофильных деталей в условиях ограниченной серийности и многокритериального подбора [10].

Остаются актуальны в промышленной практике методы сборки с использованием компенсаторов. Кафедрой «Технологии и оборудование машиностроения» московского Политеха разработан ряд образцов технологического оборудования на основе метода компенсации. Разновидностью сборки с регулированием является сборка с компенсирующими материалами (пластмассы, легкоплавкие металлы). В последние годы начинает внедряться метод, получивший в промышленности название injected metal. Сущность метода сводится к формированию искусственно большого зазора в цилиндрическом соединении и заливке его легкоплавким металлом. В Германии освоено производство оборудования, реализующего данный метод.

В условиях серийного производства может быть эффективен метод индивидуального подбора деталей. В настоящее время в нашей стране разработано теоретическое и информационное обеспечение для реализации данного метода в машиностроении
Схема экспериментальной установки для исследования процессов при вибропрессовке

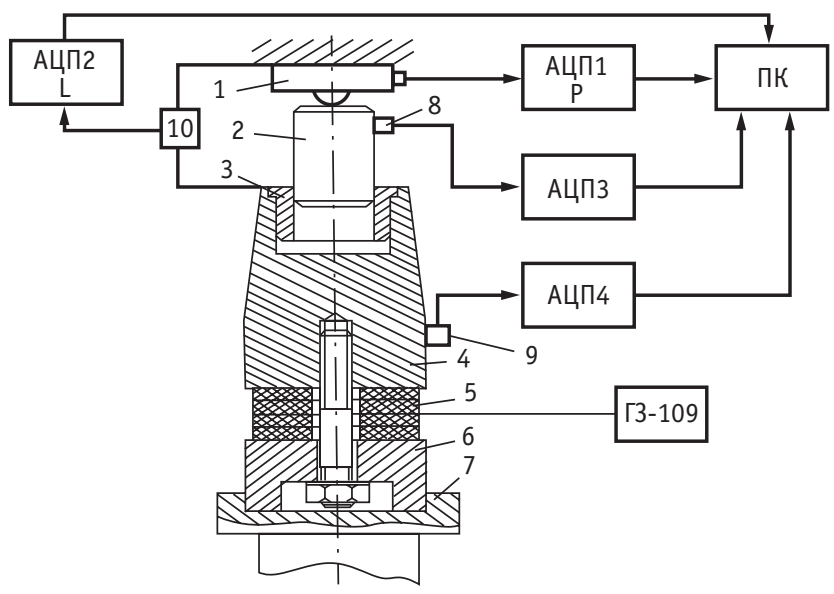

Puc. 7. Запрессовка зуба в корпус шарошки с наложением ультразвуковых колебаний (Патент РФ 2357848), где 1 - датчик силоизмерительный резистивного типа, 2, 3 - соединяемые детали (вал и втулка соответственно), 4 - концентратор колебательной энергии, 5 - пьезокерамический вибровозбудитель, 6 - противовес, 7 - шток гидроцилиндра, 8, 9 - датчики вибрации типа КВ-10, ГЗ-109 - генератор, 10 - датчик перемещения резистивного типа, АЦП1... АЦП4 - аналого-цифровой преобразователь (ЛА2USB), $P$ - усилие запрессовки, $L$ - перемещение, ПК - персональный компьютер

[11]. Метод имеет хорошие перспективы применения в станкостроении.

Проектирование сборочных операций начинают с проектирования процесса сопряжения. Для этого необходимо выбрать метод, обеспечивающий заданные технические требования на сборку и производительность сборочного процесса.

Принципиальным вопросом является выбор метода сопряжения. В последнее время получили развитие как известные методы сборки, так и новые методы. Например, появилась возможность управлять прочностью прессовых соединений на основе достижения заданных параметров качества при механической обработке сопрягаемых поверхностей [12]. В целях повышения качества прессовых соединений и повышения их нагрузочной способности может быть использован ультразвук (УЗ) (рис. 7) [13]. Применение УЗ-колебаний позволяет повысить качество соединений, в том числе за счет эффекта УЗ-сварки. Кроме того, наложение колебаний позволяет сохранить исходный профиль микронеровностей и уменьшить усилия запрессовки. Разработаны методы диагностики соединений непосредственно в процессе сборки. 


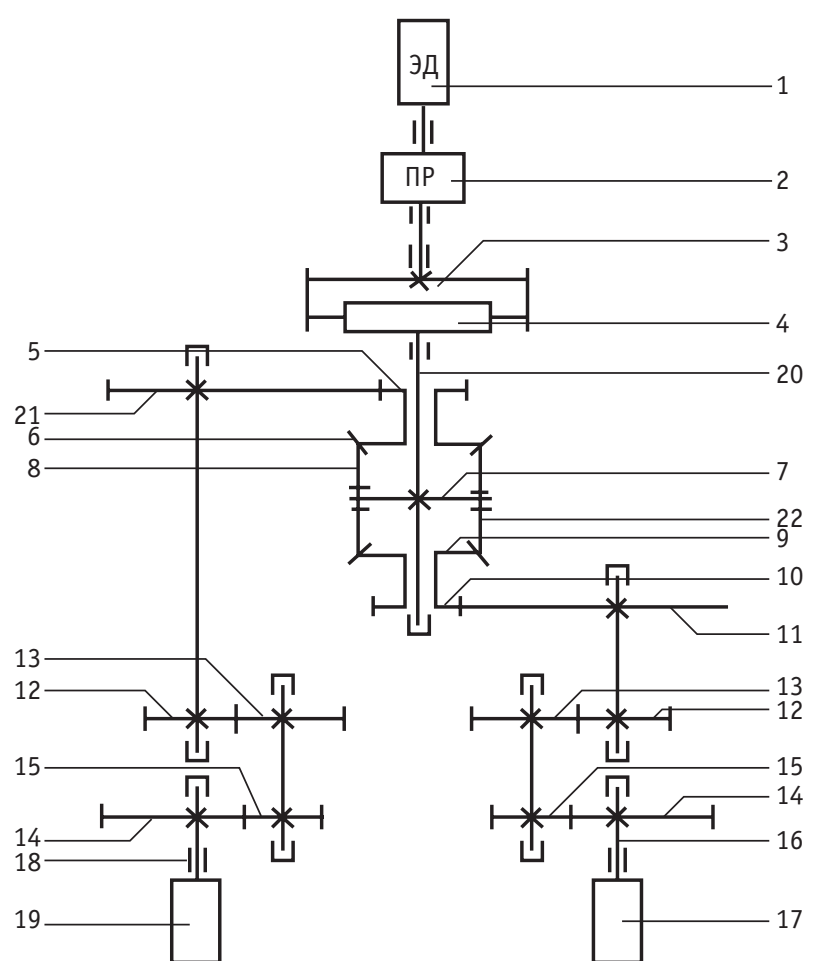

Puc. 8. Структурная схема адаптивного резьбозавинчивающего устройства

Если условия собираемости на основе размерного анализа позиции не обеспечены, то необходимо использовать адаптивную сборку. Принципиально возможны два технических решения - с пассивной и активной адаптацией. Сущность технических решений на основе адаптивной сборки достаточно широко отражена в технической литературе. Однако решения на основе активной адаптации в настоящее время еще находятся на исследовательской стадии [14]. Известен ряд успешных решений промышленного применения адаптивных устройств пассивного типа при выполнении резьбовых соединений [15] (рис. 8). Число шпинделей устройства может быть произвольным. Принцип работы основан на использовании двух кинематических цепей и обеспечении синхронности затяжки группового соединения.

Компания Atlas Сорсо предлагает инновационные решения для сборочных систем, а именно интеллектуальные гайковерты [16] (рис. 9). Предлагаемые решения охватывают как ручной инструмент, так и автоматический. Использование виртуальных станций обеспечивает возможности контроля инструмента, обмена данными и контроля аксессуаров. Интеллектуальный модуль обеспечивает хранение информации о всех выполненных операциях, простую настройку электрических гайковертов. Atlas Cорсо разработала про- граммное обеспечение ToolsTalk 2 для управления большим парком контроллеров. Графический интерфейс обеспечивает возможности оптимизации технологического оборудования, стратегия TurboTight - возможности демпфирования при выполнении инструментом операций вручную.

Проектирование автоматической сборочной операции или технологического процесса требует выполнения ряда дополнительных этапов. Основными из них являются:

$\rightarrow$ отработка изделия на технологичность с позиций автоматической сборки;

$\rightarrow$ выбор способов и устройств для автоматической загрузки собираемых деталей;

$\rightarrow$ разработка технических решений по относительному автоматическому ориентированию деталей;

$\rightarrow$ оценка выполнимости условий собираемости при автоматической сборке;

$\rightarrow$ выбор способов и технических средств автоматического контроля при выполнении автоматической сборочной операции.

Исследования в области автоматизации сборочного производства активно проводились ЭНИМС в советское время. Был создан ряд технических

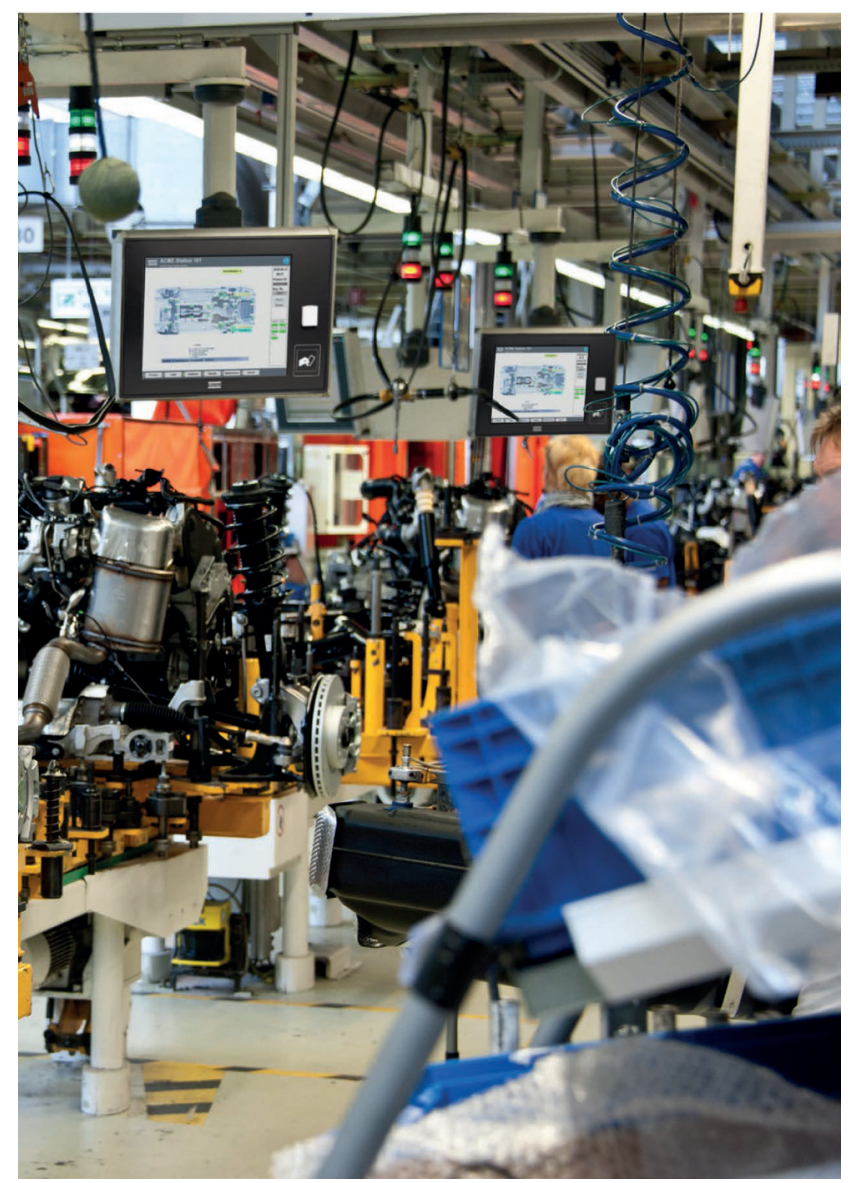

Puc. 9. Интеллектуальные гайковерты компании Atlas Сорсо на автосборочном конвейере 
систем применительно к станкостроению. Однако в условиях современной России подобные решения неизвестны.

Решение задач автоматизации сборки широко отражено в специальной технической литератуpe [17]. В целом следует отметить, что решение задач автоматизации сборки является достаточно сложным и требует наличия соответствующего опыта. Особой проблемой является ограниченность стандартного оборудования для автоматической сборки, доступного на рынке. В России нет централизованного производителя сборочного оборудования, и заказчик сталкивается с необходимостью проектирования нестандартного технологического оборудования. Вместе с тем за последние годы известен целый ряд примеров успешного решения задач автоматизации сборки небольшими научно-производственными компаниями. Например, московская фирма «ЭЛИТОН» спроектировала и изготовила автоматическую линию сборки микропробирки для анализа крови человека.

Создается специальное технологическое оборудование и автоматические линии для оборонной промышленности (патронное производство). Работа и исследования по созданию новых перспективных образцов технологического оборудования ведется в ряде вузов России.

\section{ЗАКЛЮЧЕНИЕ}

Значительная трансформация ожидает сборочное производство в ближайшие годы в связи с четвертой индустриальной революцией («Индустрия 4.0»). На первом этапе это будет оцифровка имеющегося оборудования и накопление опыта локальной автоматизации отдельных позиций. Далее это автоматизация технологических систем. Перенос технологических решений из массового производства объективная потребность, так как производства стали многономенклатурными. Во многом перспективы основаны на адаптивной и переналаживаемой сборочной оснастке [18].

Поскольку четвертая индустриальная революция это, прежде всего, автоматизация производства, то и изделия должны быть отработаны на технологичность автоматического производства. Решить проблемы четвертой индустриальной революции можно будет только при создании модульного автоматического сборочного оборудования. Подобные производства необходимы нашей стране. Значительные трансформации сборочного производства будут связаны с расширениями областей применения аддитивных технологий. Прежде всего, это связано с тем, что аддитивные технологии не требуют проектирования изделий в соответ- ствии с методами его изготовления [19]. Например, применение аддитивных технологий в перспективе может позволить исключить разделение корпуса агрегатов на несколько составных частей. Это приведет к значительному сокращению объема сборочных работ. В последние годы Союзом машиностроителей проведена большая работа по созданию профессиональных стандартов. Ряд стандартов имеет прямое или косвенное отношение к сборочному производству. Например, профессиональный стандарт «Специалист по сборке агрегатов и автомобиля».

Сборочное производство определяет уровень качества промышленной продукции. От того, насколько правильно выбраны и как реализованы технологические решения, зависит успешность изделий на рынке.

\section{ЛИТЕРАТУРА}

1. Справочник технолога-машиностроителя. В 2-х т. Т. 2 / Под ред. А.С. Васильева, А.А. Кутина; 6-е изд., перераб. и доп. - М.: Инновационное машиностроение, 2018. 818 с.

2. Безъязычный В.Ф., Семенов А.Н. Научные и методические основы сборки. Состояние теории // Сборка в машиностроении, приборостроении. 2004. № 4. С. 3-7.

3. Холодкова А.Г., Кристаль М.Г., Штриков Б.Л. и др. Технология автоматической сборки. - М.: Машиностроение, 2010. 560 с.

4. Зинченко Д. Особенности и преимущества системы ADEM области создания управляющих программ для станков с ЧПУ // СТАНКОИНСТРУМЕНT. 2019. № 2 (015). С. 66-71.

5. Попов А.М. Повышение сборочной технологичности конструкций изделий в интегрированных системах автоматизированного проектирования // Сборка в машиностроении, приборостроении. 2012. № 1. С. 14-19.

6. Вартанов М.В. Методологическое обеспечение технологичности конструкций изделий машиностроения в процессе проектирования // Автоматизация и современные технологии. 2016. С. 33-36.

7. Набатников Ю.Ф. Метод селективной сборки в условиях мелкосерийного производства // Сборка в машиностроении, приборостроении. 2012. № 9. С. 19-32.

8. Сорокин М. Н., Ануров Ю. Н. Анализ собираемости изделий типа «вал-втулка» // Сборка в машиностроении, приборостроении. 2012. № 1. C. 23-26.

9. Семенов А. Н., Сазанов А. А. Особенности обеспечения функционального качества авиационной топливной фрорсунки на этапе сборки. Материалы 2-го международного научно-технического семи- 
нара «Современные технологии сборки». - М.: МГТУ «МАМИ», 2011. С. 65-71.

10. Осипович Д.А. Разработка технологии цифровой сборки сопловых аппаратов турбины ГТД на основе измерений лопаток фотограмметрическим способом. - Дисс. к. техн. н. - Рыбинск, 2019.

11. Непомилуев В.В. Обеспечение устойчивости процесса сборки на основе индивидуального подбора деталей // Сборка в машиностроении, приборостроении. 2015. № 11. С. 7-11.

12. Федулов В.М. Исследование методов расчета натяга в прессовых соединениях на основе управления технологическими условиями обработки поверхностей. - Дисс. к. техн. н. - Рыбинск, 2013.

13. Шуваев В.Г. Адаптивное управление технологическим процессом ультразвуковой запрессовки на основе динамических характеристик формируемых соединений. - Дисс. д. техн. н. - Самара, 2013.

14. Кузнецова С. В., Симаков А. Л., Вартанов М. В., Зинина И. Н. Синтез управления процессом адаптации детали при сборке методом обратной задачи динамики // Проблемы машиностроения и автоматизации. 2019. № 3. С. 91-99.

15. Житников Ю.З., Житников Б. Ю. Обоснование универсальной кинематической схемы многошпиндельных гайковертов с произвольным чис- лом шпинделей на основе структурных схем управления процессом сборки // Современные технологии сборки». Материалы VI международного научно-технического семинара / Под ред. М.В.Вартанова. - М.: Московский Политех, 2019. C. $40-45$.

16. http://www.atlascopco.com

17. Машиностроение. Энциклопедия / Ред. совет: К.В. Фролов (пред.) и др. - М.: Машиностроение. Технология сборки в машиностроении. Т. III-5 / А. А. Гусев, В.В.Павлов; под ред. Ю. М. Соломенцева. - М., Машиностроение, 2001. 640 с.

18. Кулаков Г. А., Гусева И. А., Житников Ю. З., Рыльцев И.К. Автоматизация и механизация серийной сборки изделий. - М.: Янус-К, 2003. 324 с.

19. Гибсон Я., Розен Д., Стакер Б. Технологии аддитивного производства. - М.: ТЕХНОСФЕРА, 2018. 648 c.

\section{ВАРТАНОВ Михаил Владимирович - \\ доктор технических наук, профессор Московского политехнического университета}

Чунг ТА Чан -

аспирант Московского политехнического университета

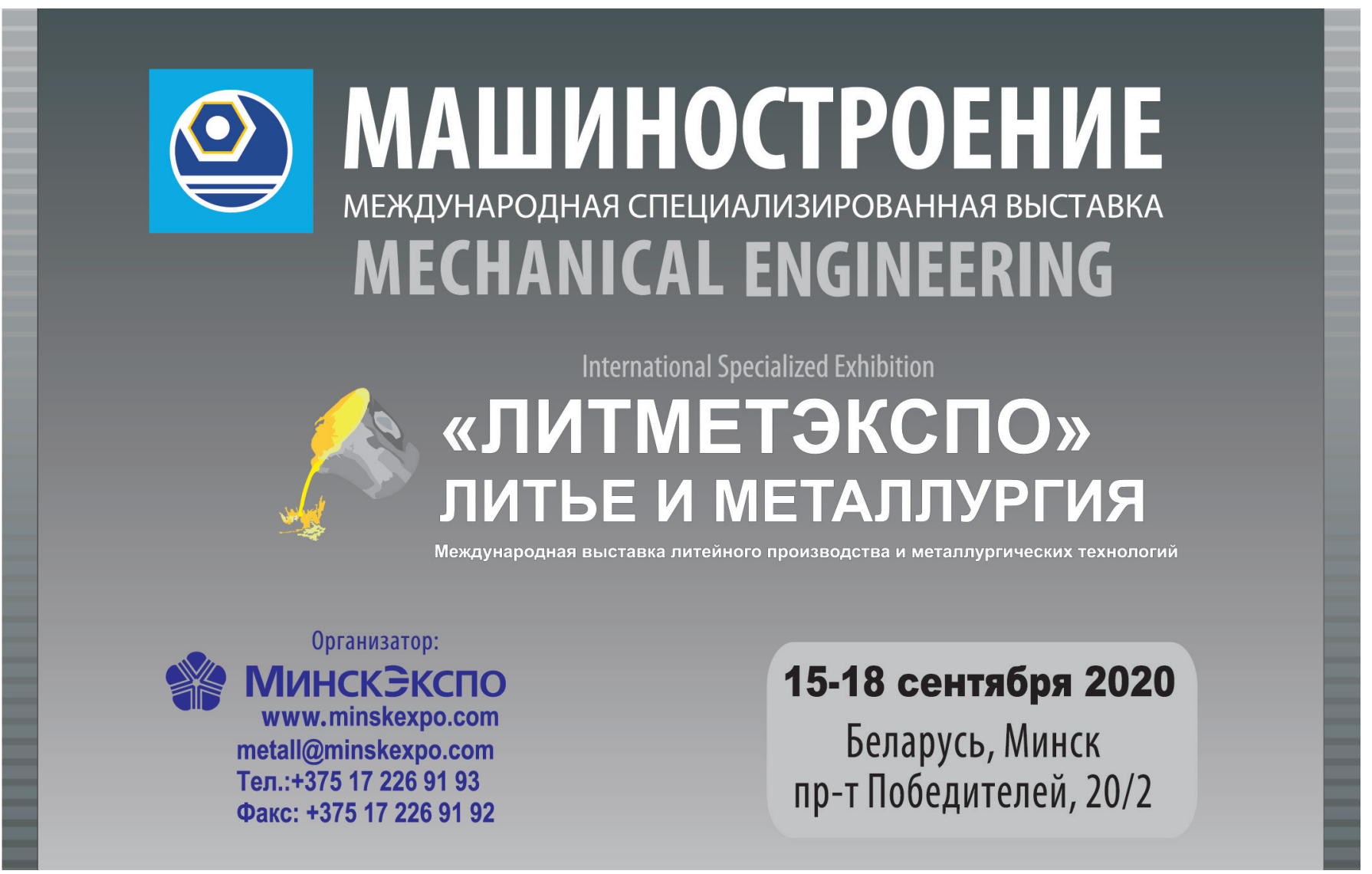

